\title{
RESEARCH ON ACETABULAR PARAMETERS, FEMORAL AND COMBINED ANTEVERSION ANGLES ON COMPUTED-TOMOGRAPHY SCAN
}

\author{
Ngo Xuan Khoa*, Tran Le Dinh Duy*, Tran Sinh Vuong*, \\ Nguyen Van Hoat**, Hoang Van Hong**, Nguyen Thai Ha Duong ${ }^{\star \star \star}$
}

\section{ABSTRACT.}

54 computed-tomography scans of 54 Vietnamese adults with at least 1 nonpathological hip at Hanoi Medical University Hospital are used on our research. The results are: Acetabular inclination angle: $37.48 \pm 4.95^{\circ}$; Acetabular anteversion angle: $17.2 \pm 5.81^{\circ}$; Femoral anteversion angle: $12.03 \pm 7.32^{\circ}$; Combined anteversion: $29.23 \pm 9.07^{\circ}$.

Keyword: Acetabulum, femoral anteversion, combined anteversion.

\section{INTRODUCTION}

Total hip arthroplasty and hemiarthroplasty have become more and more popular in treatment of hip pathologywith the number of hips replacement is increasing. However, the compliance of this procedure (such as dislocation, impingement, accelerated wear, decreased lifespan of implants ...) remains an enormous challenge for surgeons to deal with. Normal morphology of hip joint in general, acetabulum, along with femoral anteversion and combined anteversion in particular plays an important role in improving preoperative planning and postoperative hip evaluation [1]. The

\footnotetext{
* Hanoi Medical University

** Hanoi Medical University Hospital

*** University of Medicine and Pharmacy -

Vietnam National University, Hanoi

Responsible person: Tran Le Dinh Duy

Email: tranledinhduy.hmu@ gmail.com

Date of receipt: 10/6/2021

Date of scientific judgment: 21/7/2021

Reviewed date: 15/8/2021
}

development of medical imaging technology allows clinical physicians to measure the hip parameters for preoperative, intraoperative and postoperative evaluation.Among the common radiographictechniques, computedtomography scan (CT scan)is considered as reliable method to measure hip parameter pre-operatively. CT scan provides accurate information and images about the hip so that clinical surgeons are able to ensure appropriate prosthesis component and position which stabilize the prothesis and prolong their age [2], [3]. With the aim of contributing to the data of normal morphology of acetabulum on computedtomography (CT) scan, in addition to aid the surgeons with the reference data in clinical practice, the purpose of this study was to evaluate acetabular inclination, acetabular anteversion, femoral anteversion and combined anteversion on CTscans of Vietnamese adults.

\section{MATERIAL AND METHOD}

\subsection{Subjects}

CT scan images which started from the top of the pelvis to below the tibial tubercle and stored on Picture Archiving and Communication System (PACS) of 54 patients whose age from 25 to 96 (with mean age and SD are 61 and 16.62 respectively) with no hip pathology on at least one side at Radiology Center of Hanoi Medical University Hospital in the period from August 2018 to April 2020. 


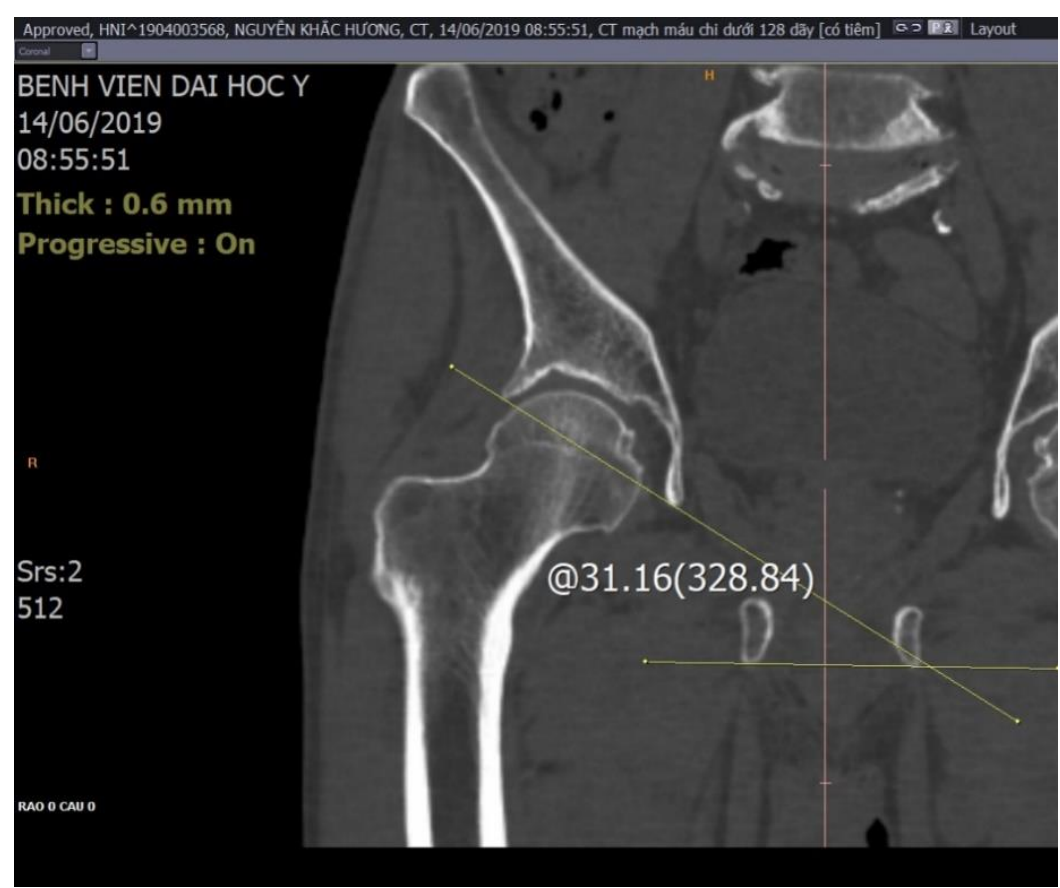

Image 1. A sample of acetabular inclination

\subsection{Method}

- Acetabular inclination is determined on anteversion is measured by determined by coronal slice contains femoral head center. single-sliced axial method. Combined Acetabular anteversion is in which the anteversion is calculated by the sum of distance between acetabular anterior margin acetabular anteversion and femoral and posterior margin is greatest. Femoral anteversion.

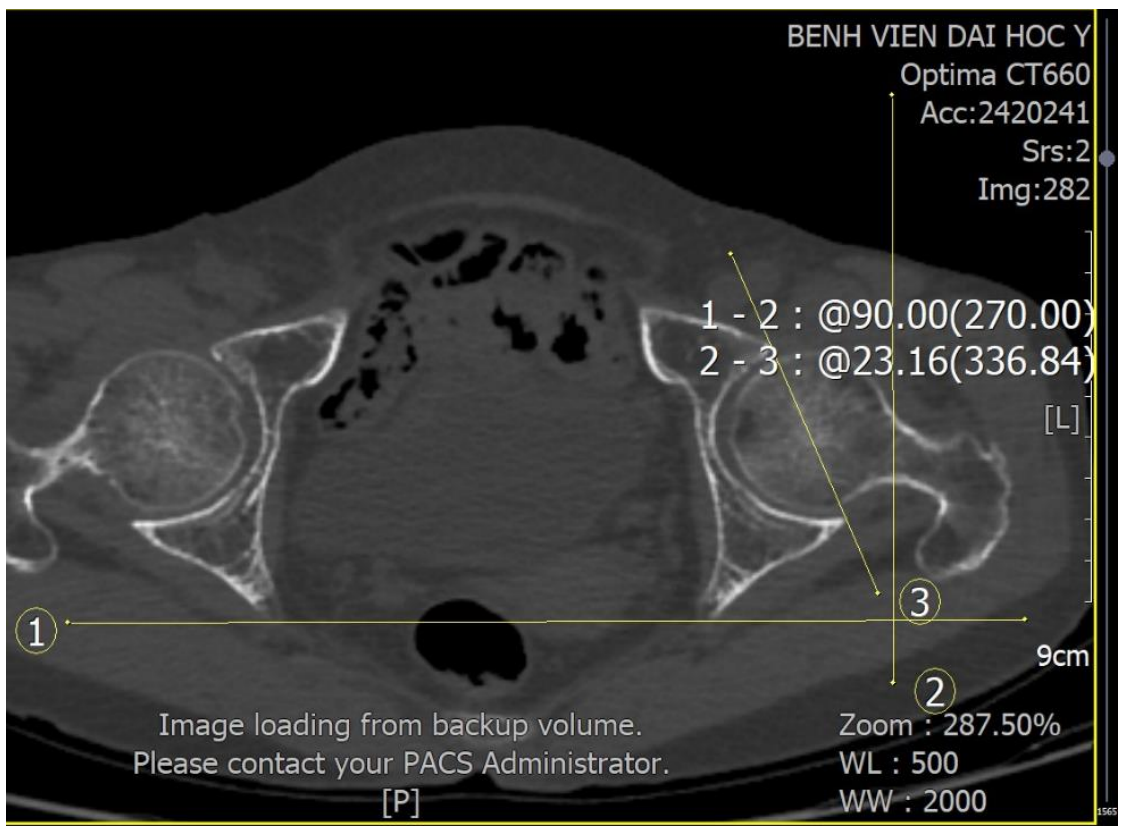

Image 2. A sample of acetabular anteversion 
- Data of the parameters are measured on PACS, recorded on medical study records and analyzed by SPSS 20.0 and Microsoft Excel Office 2016. Normal distribution of variables is tested by Kolmogorov-Smirnov test. The comparisons between variables are tested by t-test and paired t-test for variations with normal distribution, by Mann-Whitney$\mathrm{U}$ test for variables with abnormal distribution. Spearman and Pearson correlation are used to test relations between variables (Figure 1).

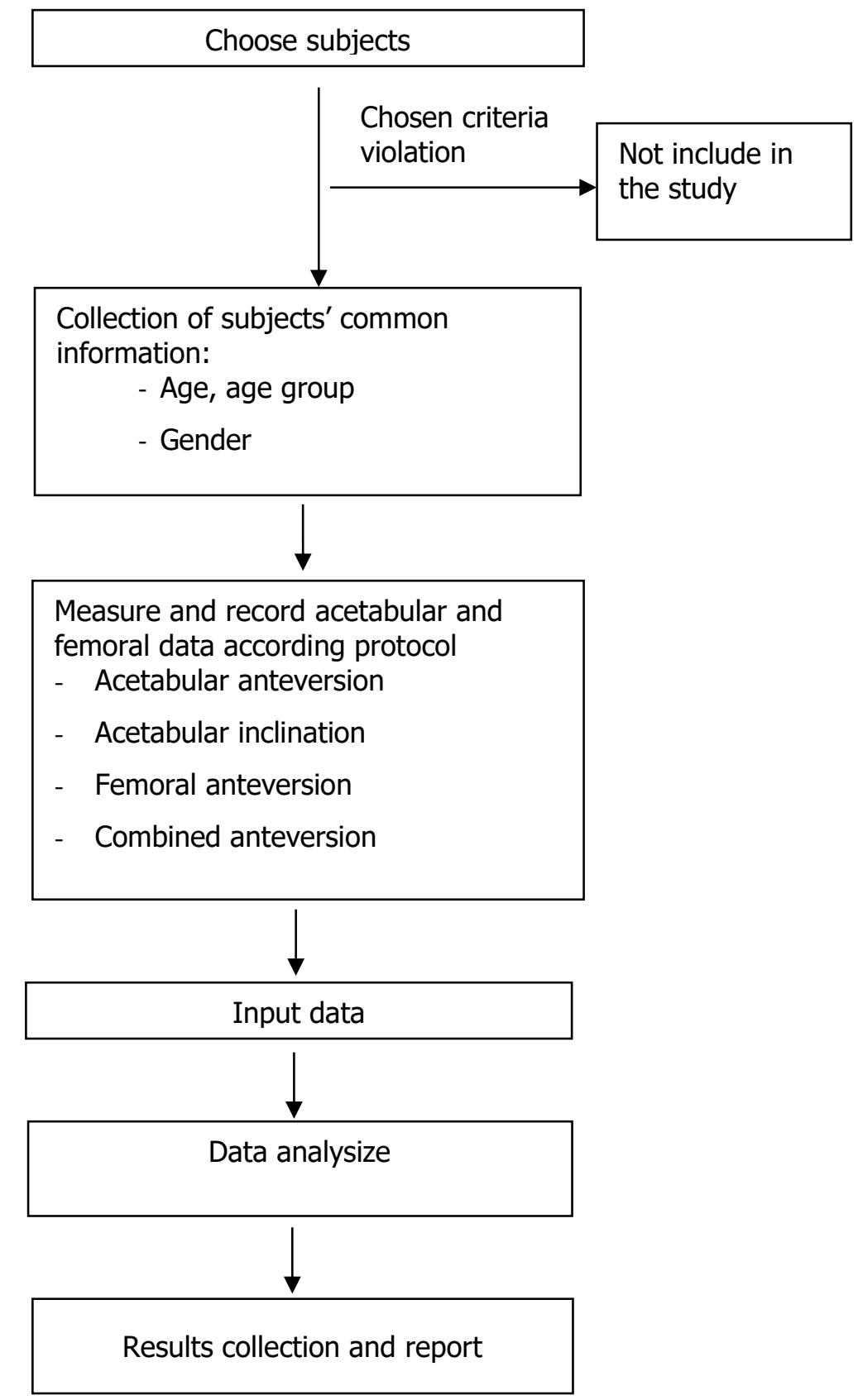

Figure 1. Data record diagram. 


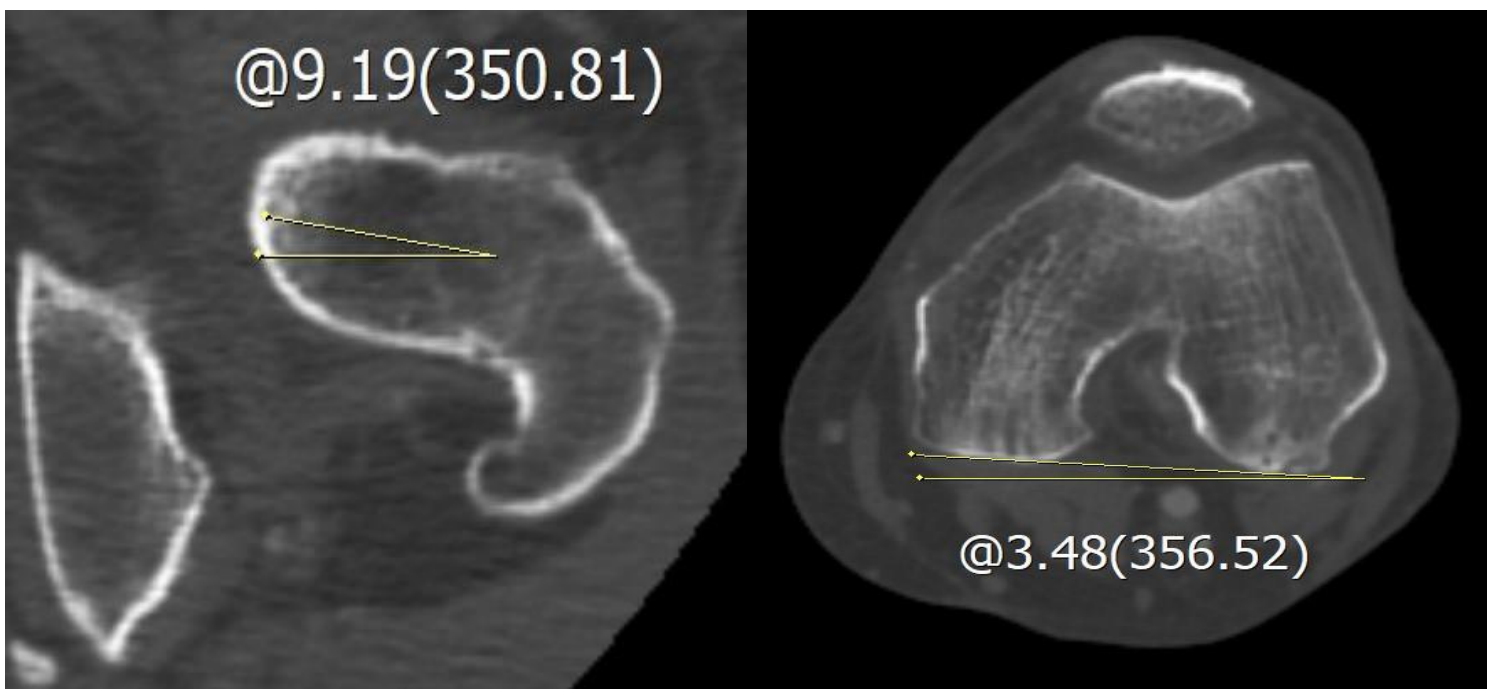

Image 3. A sample of femoral anteversion measured by single-sliced axial method

III. RESULT AND DISCUSSION

Table 1. Sex-based comparison of acetabular parameters and anteversion angles

\begin{tabular}{|c|c|c|c|c|c|}
\hline & & $\begin{array}{c}\text { Acetabular } \\
\text { inclination }\left({ }^{\circ}\right)\end{array}$ & $\begin{array}{c}\text { Acetabular } \\
\text { anteversion } \\
\left({ }^{\circ}\right)\end{array}$ & $\begin{array}{c}\text { Femoral } \\
\text { anteversion } \\
\left({ }^{\circ}\right) \\
\end{array}$ & $\begin{array}{c}\text { Combined } \\
\text { anteversion } \\
\left({ }^{\circ}\right)\end{array}$ \\
\hline \multirow[t]{3}{*}{ This study } & Total & $37.48 \pm 4.95$ & $17.2 \pm 5.81$ & $12.03 \pm 7.32$ & $29.23 \pm 9.07$ \\
\hline & Male & $36.89 \pm 5.17^{*}$ & $16.08 \pm 5.65^{*}$ & $10.47 \pm 6.11^{*}$ & $26.54 \pm 8.03^{*}$ \\
\hline & Female & $39.25 \pm 3.8^{*}$ & $20.51 \pm 5.04 *$ & $16.66 \pm 8.69 *$ & $37.17 \pm 7.22^{*}$ \\
\hline \multirow{3}{*}{$\begin{array}{l}\text { Tran Trung } \\
\text { Dung et al. } \\
{[4]}\end{array}$} & Total & $38.5 \pm 3.9$ & $17.2 \pm 7.0$ & $13.7 \pm 10.4$ & $30.8 \pm 13.2$ \\
\hline & Male & $38.6 \pm 3.8$ & $16.3 \pm 7.1$ & $13.3 \pm 11.7$ & $29.6 \pm 14.8$ \\
\hline & Female & $38.3 \pm 4.3$ & $18.7 \pm 6.8$ & $14.3 \pm 7.8$ & $33.0 \pm 9.8$ \\
\hline \multirow{3}{*}{$\begin{array}{l}\text { Aditya V. } \\
\text { Maheshwarie } \\
\text { t al. [5] }\end{array}$} & Total & - & $19.1 \pm 5.0$ & $8.0 \pm 4.7$ & $27.1 \pm 6.3$ \\
\hline & Male & - & 17.3* & 7.3 & 24.6* \\
\hline & Female & - & $20.8^{*}$ & 8.7 & $29.5^{*}$ \\
\hline \multirow{3}{*}{$\begin{array}{l}\text { Nan Jiang et } \\
\text { al. [6] }\end{array}$} & Total & - & $18.79 \pm 5.30$ & $10.62 \pm 9.02$ & - \\
\hline & Male & - & $18.27 \pm 5.22 *$ & $9.31 \pm 8.58^{*}$ & \\
\hline & Female & - & $20.44 \pm 5.26^{*}$ & $14.76 \pm 9.13 *$ & \\
\hline
\end{tabular}

*Significant at the 0.05 level

Regarding of gender, acetabular parameters, femoral anteversion and combined anteversion of male is lesser than female with the 0.05 level of significant. This study's results are different from the study of Tran Trung Dung et al., where there is no different of hip joint's parameters between two genders. The study of Aditya $\mathrm{V}$.
Maheshwari et al. indicates that there is no difference in sex-based femoral anteversion comparison while there is difference in acetabular anteversion and combined anteversion. The sex-based difference in acetabular anteversion and femoral anteversion observed in the study of Nanjiang et al. 


\section{VIETNAM MEDICAL JOURNAL №1\&2/2021}

Table 2. Side-based comparison of acetabular parameters and anteversion angles

\begin{tabular}{|c|c|c|c|c|c|}
\hline & & $\begin{array}{l}\text { Acetabular } \\
\text { inclination }\left(^{\circ}\right)\end{array}$ & $\begin{array}{l}\text { Acetabular } \\
\text { anteversion }\left({ }^{\circ}\right)\end{array}$ & $\begin{array}{l}\text { Femoral } \\
\text { anteversion } \\
\left({ }^{\circ}\right)\end{array}$ & $\begin{array}{l}\text { Combined } \\
\text { anteversion }\left({ }^{\circ}\right)\end{array}$ \\
\hline \multirow[t]{3}{*}{ This study } & Total & $37.48 \pm 4.95$ & $17.2 \pm 5.81$ & $12.03 \pm 7.32$ & $29.23 \pm 9.07$ \\
\hline & Left & $36.95 \pm 4.87$ & $16.79 \pm 5.87$ & $12.15 \pm 7.38$ & $28.94 \pm 8.61$ \\
\hline & Right & $38.01 \pm 5.03$ & $17.59 \pm 5.79$ & $11.91 \pm 7.34$ & $29.5 \pm 9.58$ \\
\hline \multirow{3}{*}{$\begin{array}{l}\text { Aditya V. } \\
\text { Maheshwari } \\
\text { et al. }\end{array}$} & Total & - & $19.1 \pm 5.0$ & $8.0 \pm 4.7$ & $27.1 \pm 6.3$ \\
\hline & Left & - & 18.9 & 7.4* & 27.6 \\
\hline & Right & - & 19.2 & $8.7 *$ & 26.6 \\
\hline \multirow{3}{*}{$\begin{array}{l}\text { Nan Jiang } \\
\text { et al. }\end{array}$} & Total & - & $18.79 \pm 5.30$ & $10.62 \pm 9.02$ & - \\
\hline & Left & - & $18.43 \pm 5.21^{*}$ & $10.93 \pm 9.13$ & - \\
\hline & Right & - & $19.10 \pm 5.38 *$ & $10.41 \pm 8.85$ & - \\
\hline
\end{tabular}

*Significant at the 0.05 level

In term of side comparison, our studyfound no asymmetry in the acetabular parameters and anteversion angles. In the study of Aditya V. Maheshwari et al., there was difference in femoral anteversion between right and left hip, the difference was not found in acetabular anteversion and combined anteversion. Nanjiang et al.'s research show that there was difference in acetabular anteversion in two sides while there was no difference in femoral anteversion. The side-based difference may be result from leg dominance. The dominant lower limb, usually the right, places greaterbiomechanical stresses and loads to the dominantso the parameters and angle of femoral neck, head and acetabulum on the dominant side tends to be smaller than the

other side [7].

We found that combined anteversion has a positive correlation with femoral anteversion and acetabular anteversion (correlation index are 0.592 and 0.769 respectively), and there were no correlations between other couples of parameters. Leonard T. Buller et al. found correlation between femoral anteversion and acetabular inclination as well as femoral anteversion and acetabular anteversion [8]. Reikeråls. et al's study on 47 persons with normal hip joint and 39 persons with osteoarthritis found that there was no corelation between femoral anteversion and acetabullar anteversion, and the existence of this corelation may contribute to the osteoarthritis of hip [9].

Table 3. Correlations between acetabular parameter and anteversions

\begin{tabular}{|l|c|c|c|c|}
\hline Parameter & $\begin{array}{c}\text { Acetabular } \\
\text { inclination }\end{array}$ & $\begin{array}{c}\text { Acetabular } \\
\text { anteversion }\end{array}$ & $\begin{array}{c}\text { Femoral } \\
\text { anteversion }\end{array}$ & $\begin{array}{c}\text { Combined } \\
\text { anteversion }\end{array}$ \\
\hline $\begin{array}{l}\text { Acetabular } \\
\text { inclination }\end{array}$ & 1 & & & \\
\hline $\begin{array}{l}\text { Acetabular } \\
\text { anteversion }\end{array}$ & 0.01 & 1 & & \\
\hline $\begin{array}{l}\text { Femoral } \\
\text { anteversion }\end{array}$ & -0.66 & -0.59 & 1 & \\
\hline $\begin{array}{l}\text { Combined } \\
\text { anteversion }\end{array}$ & $0.592 *$ & -0.047 & $0.769 *$ & 1 \\
\hline
\end{tabular}

*Significant at the 0.01 level 


\section{CONCLUSION}

- Mean and standard deviation of femoral anteversion are $12.03 \pm 7.32^{\circ}$, age-based difference is observed between the age group under 60 and 60 and above.

- Mean and standard deviation of acetabular anteversion are 17.2 $\pm 5.81^{\circ}$.

- Mean and standard deviation of acetabular inclination are $37.48 \pm 4.95^{\circ}$.

- Mean and standard deviation of combined anteversion are $29.23 \pm 9.07^{\circ}$.

\section{REFERENCES}

1. Dimitriou.D., Tsai.T.-Y., Yue.B., et al. (2016). Side-to-side variation in normal femoral morphology: 3D CT analysis of 122 femurs. Orthopaedics \& Traumatology: Surgery \& Research, 102(1), p. 91-97.

2. Boissonneault.A.R., Hiranaka.T., Roberson.J.R., et al. (2017). A Validated Single-View Radiographic Alternative to Computed Tomography for the Measurement of Femoral Anteversion: A MethodComparison Study. The Journal of Arthroplasty, 32(3), p. 1018-1023.

3. Sugano,N.,btv. (2018), Computer Assisted Orthopaedic Surgery for Hip and Knee, Springer Singapore, Singapore.

4. Tran Trung.D., Pham Trung.H., Truong Cong.M., et al. (2019). The anatomical characteristics of Vietnamese adult hip joint: a multiplanar reconstruction computer tomographic study. Muscle Ligaments and Tendons Journal, 09(01), p. 165.

5. Maheshwari.A. V., Zlowodzki.M.P., Siram.G., et al. (2010). Femoral neck anteversion, acetabular anteversion and combined anteversion in the normal Indian adult population: A computed tomographic study. Indian Journal of Orthopaedics, 44(3), p. 277-282.

6. Jiang.N., Peng.L., Al-Qwbani.M., et al. (2015). Femoral version, neck-shaft angle, and acetabular anteversion in Chinese Han population: a retrospective analysis of 466 healthy adults. Medicine, 94(21), p. e891.

7. Gilligan.I., Chandraphak.S., and Mahakkanukrauh.P. (2013). Femoral neckshaft angle in humans: Variation relating to climate, clothing, lifestyle, sex, age and side. Journal of Anatomy, 223(2), p. 133-151.

8. Buller.L.T., Rosneck.J., Monaco.F.M., et al. (2012). Relationship between proximal femoral and acetabular alignment in normal hip joints using 3-dimensional computed tomography. American Journal of Sports Medicine, 40(2), p. 367-375.

9. Reikeråls.O., Bjerkreim.I., and Kolbenstvedt.A. (1983). Anteversion of the Acetabulum and Femoral Neck in Normals and in Patients with Osteoarthritis of the Hip. Acta Orthopaedica Scandinavica, 54(1), p. 18-23. 